\title{
STIMULATION OF BARLEY (HORDEUM VULGARE L.) GROWTH WITH LOCAL TRICHODERMA SP. ISOLATES
}

\author{
KÜÇÜK, Ç. ${ }^{*}{ }^{*}$ CEVHERI, C. ${ }^{1}-$ MUTLU, A. ${ }^{2}$ \\ ${ }^{l}$ Department of Biology, Faculty of Arts and Science, Harran University, Şanliurfa, Turkey \\ ${ }^{2}$ Akcakale Vocational College, Harran University, Şanlıurfa, Turkey \\ *Corresponding author \\ e-mail: ckucuk@harran.edu.tr; phone: +90-414-318-3567 \\ (Received 24 $4^{\text {th }}$ Jan 2019; accepted $27^{\text {th }}$ Feb 2019)
}

\begin{abstract}
Trichoderma species are used as biological control agents against plant pathogenic fungi. In addition, some isolates of Trichoderma species produce metabolites that promote plant growth. In this study, it was aimed to determine the effect of local isolates of Trichoderma sp. and a commercial microbial fertilizer containing Trichoderma harzianum on the growth of barley. The experiment was carried out according to the randomized plots experimental design. Barley seeds were inoculated with spore solutions of local isolates and then compared with controls (without inoculation and commercial fertilizer). Plant height, root length, root dry weight, shoot dry weight and chlorophyll content were determined. The effects of isolates were different. In this study, plant height was increased with the application of local isolates. The difference between isolates was statistically significant. Isolates were determined to have positive effects on barley growth.
\end{abstract}

Keywords: Trichoderma sp., plant growth promoting, barley, biostimulant, photosynthetic pigment

\section{Introduction}

One of the alternatives used in fertilization programs in environmentally friendly production techniques is microbial fertilization. Microbial fertilizers are defined as commercial formulations of live microorganisms which are involved in the removal of plant nutrients necessary for the plant used in agricultural production (Akladious and Abbas, 2014). Microbial fertilizers are used in agriculture for many purposes, such as increasing plant growth, yield, and nutrient intake, controlling soil-borne diseases, decomposing organic residues, improving soil structure and productivity and providing resistance to diseases and pests (de Santiago et al., 2011; Ousley et al., 1993). This strengthening effect in plants can also lead to a decrease in the use of pesticides and fertilizers. In many developed and developing countries, intensive studies have been carried out to obtain biological or microbial fertilizer formulations considering clean environment and healthy crop production (Kucharski et al., 1996; Vessey, 2003). Microorganisms such as Bacillus spp., Azotobacter spp., Trichoderma spp., Rhizobium spp., Azospirillum spp. and Saccharomyces spp. are used as microbial fertilizers (Sharma et al., 2003; Vazquez et al., 2000).

Trichoderma is a soil fungus found in many parts of the world (Hoyos-Carvajal et al., 2009). Trichoderma spp. are the most studied microorganisms which are used as microbial fertilizers and biological control agents against fungal pathogens (HoyosCarvajal et al., 2009).

In addition to its ability to promote plant growth, Trichoderma spp. isolates have been used for many years in the biological control of many fungal induced plant diseases (Woo et al., 2006). It is known that Trichoderma spp., which is colonized in the root, stimulates 
resistance to plant diseases as well as it promotes shoot and root growth, increases yield, resistance to abiotic stress conditions, promotes nutrient intake and use and increases photosynthesis (Inbar et al., 1994; Yedidia et al., 2001; Harman et al., 2004; Harman, 2006).

Datnoff and Pernezny (2001) reported that Trichoderma spp. preparates were increased the growth of tomato seedlings in greenhouse and field conditions. In recent years the use of microorganisms that promote plant growth has increased. Therefore, studies are carried out to reduce environmental pollution by reducing the use of chemical fertilizers (Kucharski et al., 1996; Hermosa et al., 2012). Some Trichoderma isolates stimulated the plant against abiotic and biotic factors, increased the germination rate and percentage of the seeds, the fertility of the fertilizers, the nutrient intake from the soil and directly affected the plants (Shoresh ve ark., 2010).

de Santiago et al. (2011) and Zhang et al. (2013) were reported that the application of Trichoderma species in various plants were increased the root growth of the plants, yield, leaf area, the weight of fresh seedlings. Dissolution of insoluble minerals for plant growth (Altomare, 1999; Küçük et al., 2008; Rawat et al., 2011), indole acetic acid, siderophore, 1-aminocyclopropane-1-carboxylic acid (ACC) deaminase production (Viterbo et al., 2010) as effective factors in plant growth were studied.

It is known that nitrogenous fertilizers accumulate in agriculture crops which increase nitrate ratio in drinking and irrigation waters and adversely affect human and animal health (Bashan, 1998; Rennie and Heffer, 2003). The use of microorganisms in agriculture has been gaining importance in recent years in order to eliminate these problems and to reduce the use of chemical fertilizers. Barley has an important in the agriculture of Turkey and has an important role in the reduction of fallow land (Karakaya et al., 2016).

The cultivation and production of barley is done in all regions of Turkey. While most of the barley produced in Turkey is used in feed industry, some are used directly in animal feed and some in beer industry. Since barley is mostly used as animal feed, the seeds are inoculated with microorganisms in order to increase the protein content in barley (Karakaya et al., 2016). In this study was carried out in greenhouse conditions to investigate the effects of three different Trichoderma sp. isolates and commercial microbial fertilizer containing $T$. harzianum applied to seed on the growth of barley plant.

\section{Materials and methods}

The local isolates (T4, T7 and T11 isolates) of Trichoderma sp., were obtained from the Microbiology laboratory of Harran University. The isolates (Fig. 1) were stored in Potato Dextrose Agar (PDA) media and stocked at $+4{ }^{\circ} \mathrm{C}$ until use. Trichoderma harzianum Rifaii KRL-AG2 was used as a commercial microbial fertilizer. Commercial microbial fertilizer was received from Biyoglobal A. Ş., Turkey.

\section{The effect of isolates on plant growth}

Barley (Hordeum vulgare L.) seeds were immersed in $70 \%$ ethanol for 3 minutes, $2 \%$ $\mathrm{NaOCl}$ for 2 minutes and washed several times with sterile distilled water. Trichoderma sp. isolates were incubated in PDA containing petri dishes for 7 days at $25{ }^{\circ} \mathrm{C}$. Spore solutions of isolates $\left(10^{6} \mathrm{cfu} / \mathrm{ml}\right)$ were then prepared. Sterilized seeds were incubated for 3 hours in spore solution and sown in sterile soil. Soils were taken from Osmanbey Campus Harran University, Turkey where no adaptation was made before. The soil 
samples were sterilized in autoclave for consecutive three days. Steriled soils were filled in $2 \mathrm{~kg}$ pots. The diamonium phosphate fertilizer $(10 \mathrm{~kg} / \mathrm{da})$ was given to the soil. Plants were grown in natural light greenhouse for 1 month. Akhisar varieties were used as barley varieties. The seeds were obtained from GAP Research Institute.

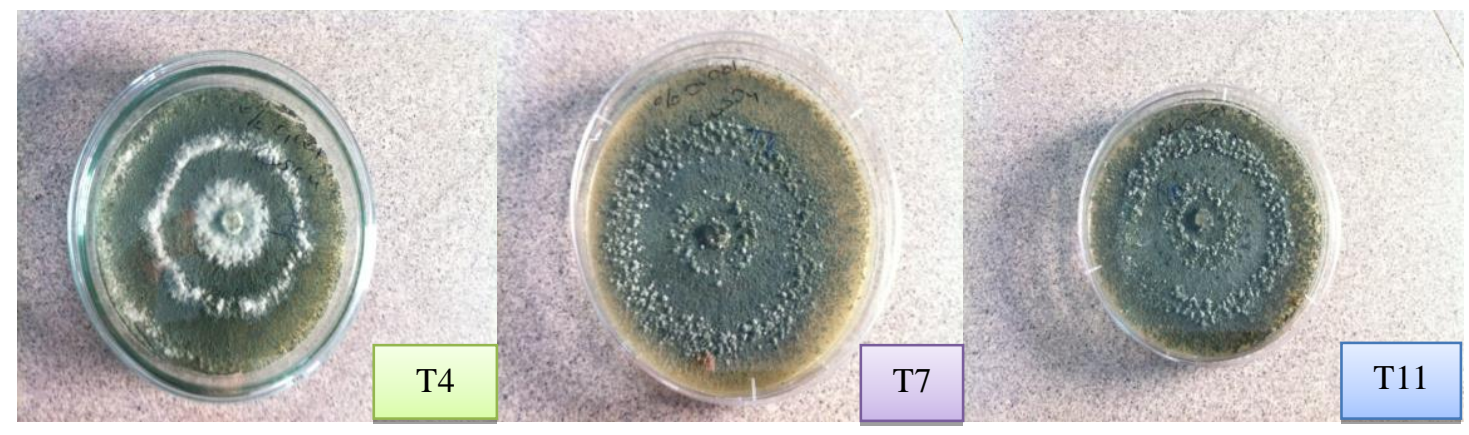

Figure 1. Trichoderma sp. isolates used in the study

In each pot, plant height, shoot dry weight, root dry weight and root lenght were determined. The photosynthetic pigments extracted from the leaves (chlorophyll a, b, carotenoid) were made according to Akladious and Abbas (2014).

The soil $\mathrm{pH}$ was determined by $\mathrm{pH}$ meter in a 1: 2.5 soil mixture. The organic matter content of the soil was made according to the method determined by Walkley (1964). The distribution of soil particles was determined by the Bouyoucours hydrometer (Bouyoucos, 1951) and the total nitrogen content was determined by the Kjeldahl method (Bremner, 1982).

\section{Indole acetic acid (IAA) production of isolates}

Spore solutions of Trichoderma isolates $\left(10^{6}\right.$ conidia / ml $)$ were prepared. Spore solutions $(0.1 \mathrm{ml})$ were inoculated onto the agar surface and coated with a nitrocellulose membrane, petri dishes were incubated at $25^{\circ} \mathrm{C}$ for 7 days. Then, the membrane disc was removed, the filter paper (Whatman no 2) saturated with the salkowski reagent was placed. After 5-10 minutes, IAA production by isolates was determined by color change (HoyosCarvajal et al., 2009).

\section{Solubility of phosphorus}

The isolates were inoculated into the medium containing $0.1 \mathrm{~g} / \mathrm{l}$ bromocresol purple using tribasic calcium phosphate as the phosphorus source. 48 hours after incubation, the color of the medium from purple to yellow showed that the isolates can dissolve the phosphate (Vazquez et al., 2000).

\section{Statistical analysis}

The data obtained from the study were analyzed in JMP 11 statistics program.

\section{Results and discussion}

In this study, the effect of three isolates of Trichoderma sp. on the growth of barley and some plant growth-promoting metabolites were investigated. Phosphate solubility 
and indole acetic acid production as a metabolite were evaluated. Phosphorus is a very hard to reach nutrient. Its low amount adversely affects plant growth (Raghothama, 1999). All of our isolates were able to dissolve phosphorus.

Siderophores are iron chelating ligands which may be useful to plants by increasing the solubility of ferric iron (Fe III) not present for plant nutrition. This element is assimilated by stem cells in reduced form (Fe II). Fe III is dominant especially in the aerated soils. Trichoderma may reduce Fe (III) by chelators such as siderophores (Altamore et al., 1999; Jalal et al., 1987; Zhao and Zhang, 2015). Jalal et al. (1987) reported that $T$. virens produced hydroxamate siderophore as a $\mathrm{Fe}$ III chelating mechanism. According to these researchers, Trichoderma sp. transformation into solvable forms by chelation and reduction. Both mechanisms play a role in the stimulation of growth and biocontrols of plant pathogens (Qi et al., 2012; Vessey, 2003; Woo et al., 2006). Siderophores can support rhizosphere colonization and plant growth in synergy with other substances and are the effective mechanism of some microorganisms to increase plant growth (Sharma et al., 2003).

Production of plant growth hormones is another mechanism that increases the growth of plants. The tested isolates produced auxin hormone, which increased plant growth. It has been reported that Trichoderma isolates synthesize auxin hormones in their interaction with both plant pathogens and plants (Hermosa et al., 2012; Shayakhmetov, 2001). In this study, it was determined that isolates produced indole acetic acid.

In pot experiment, the $\mathrm{pH}$ of the soil used is 7.8 . The clay ratio is $53.12 \%$, silt ratio is $24 \%$ and sand ratio is $22.8 \%$. The organic matter content of the soil is $1.71 \%$, total nitrogen is $0.18 \%$ and $\mathrm{K}_{2} \mathrm{O}$ content is $97.2 \mathrm{~kg} /$ da. The effects of Trichoderma applications on barley plants are given in Table 1. When Table 1 is examined, the effects of Trichoderma applications differed. It was determined that the applications increased the plant height statistically $(\mathrm{p}<0.05)$.

Table 1. Effects on barley shoot and root dry weight, root lenght, plant height of treatments

\begin{tabular}{c|c|c|c|c}
\hline Treatment & $\begin{array}{c}\text { Plant height } \\
(\mathbf{c m})\end{array}$ & $\begin{array}{c}\text { Shoot dry weight } \\
\text { (g/plant) }\end{array}$ & $\begin{array}{c}\text { Root dry weight } \\
\text { (g/plant) }\end{array}$ & $\begin{array}{c}\text { Root lenght } \\
(\mathbf{c m})\end{array}$ \\
\hline $\mathrm{T} 4$ & $18.3 \mathrm{a}$ & $14.6 \mathrm{~b}$ & $2.66 \mathrm{a}$ & $15.5 \mathrm{a}$ \\
$\mathrm{T} 7$ & $16.7 \mathrm{ab}$ & $13.9 \mathrm{bc}$ & $2.78 \mathrm{a}$ & $14 \mathrm{ab}$ \\
$\mathrm{T} 11$ & $16.3 \mathrm{ab}$ & $16.4 \mathrm{a}$ & $2.05 \mathrm{ab}$ & $13.1 \mathrm{~b}$ \\
Commercial fertilizer & $16.2 \mathrm{ab}$ & $12.5 \mathrm{c}$ & $2.69 \mathrm{a}$ & $10.8 \mathrm{c}$ \\
control & $14.7 \mathrm{~b}$ & $10.6 \mathrm{~d}$ & $1.33 \mathrm{~b}$ & $10.3 \mathrm{c}$ \\
\hline
\end{tabular}

Trichoderma sp. T4 application was the longest plant height $(18.3 \mathrm{~cm}) \mathrm{cm}$, followed by $\mathrm{T} 7$ and T11 isolates respectively (Fig. 2). The shortest plant height was obtained from untreated control application $(14.7 \mathrm{~cm})$. The effect of Trichoderma applications on root length in barley plants was statistically significant $(p<0.01)$. The highest root length was taken from T4 application. The effects of isolates on barley shoot and root dry weight were different. The highest shoot dry weight was obtained from T11 application. All of the applications increased root weight relative to control (Table 1). Trichoderma isolates were found to be effective on chlorophyll content in barley plants $(\mathrm{p}<0.01)$ (Table 2). A significant increase in plant growth of cucumber plants inoculated with Trichoderma harzianum was determined (Yedidia et al., 2001). 


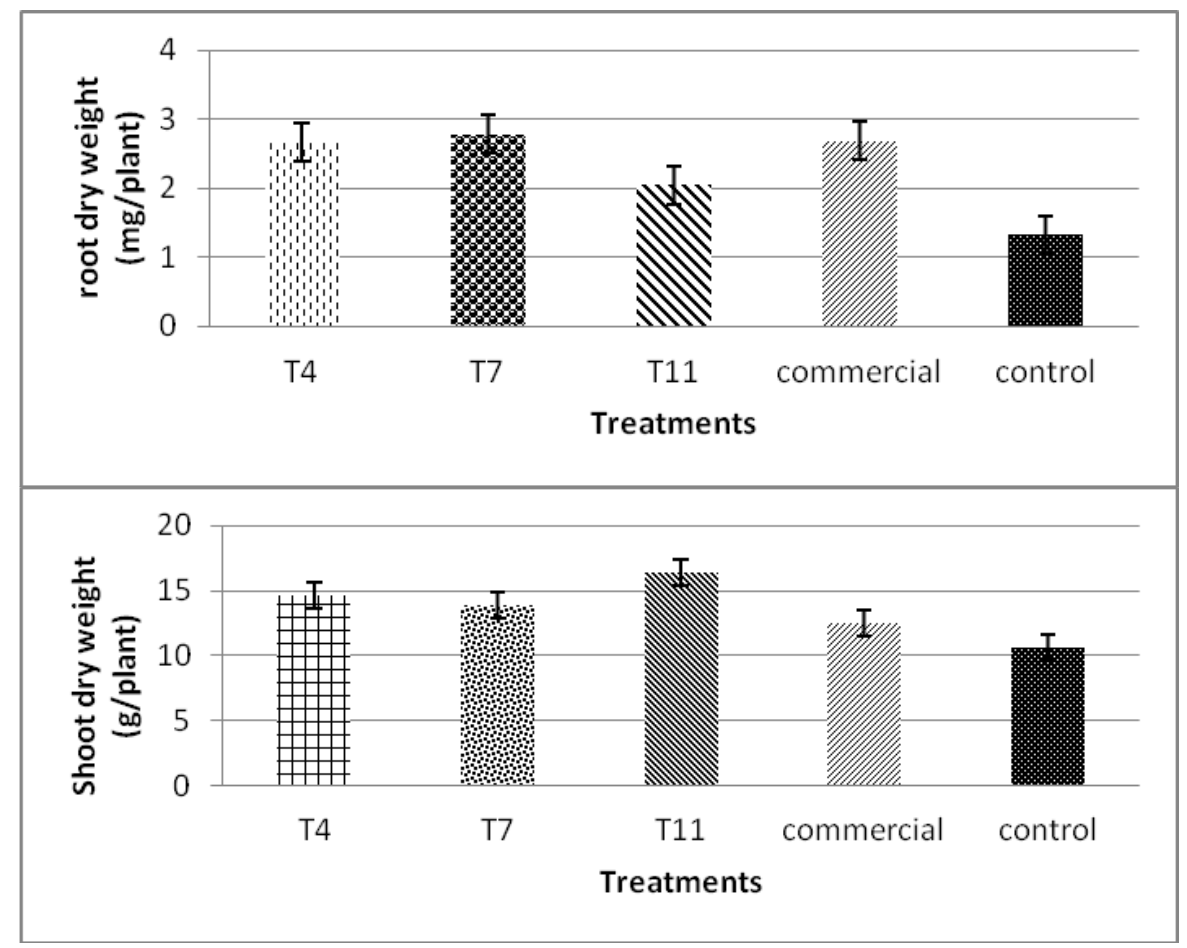

Figure 2. Effects of Trichoderma applications on root and shoot dry weights of barley

Table 2. Effects of Trichoderma applications on photosynthetic pigments of barley plants

\begin{tabular}{c|c|c|c|c}
\hline Treatment & $\begin{array}{c}\text { (A663 and A645) } \\
\text { chlorophyll-a } \\
\text { (mg/ fresh wt.) }\end{array}$ & $\begin{array}{c}\text { (A645 and A663) } \\
\text { chlorophyll-b } \\
\text { (mg/ fresh wt.) }\end{array}$ & $\begin{array}{c}\text { (A645 and A663) } \\
\text { total chlorophyll } \\
\text { (mg/ fresh wt.) }\end{array}$ & $\begin{array}{c}\text { (A480 and A510) } \\
\text { carotenoid } \\
\text { (mg/ fresh wt.) }\end{array}$ \\
\hline T4 & $1.554 \mathrm{~b}$ & $2.705 \mathrm{c}$ & $2.705 \mathrm{c}$ & $1.214 \mathrm{~b}$ \\
$\mathrm{~T} 7$ & $1.580 \mathrm{a}$ & $2.946 \mathrm{a}$ & $2.946 \mathrm{a}$ & $1.201 \mathrm{c}$ \\
$\mathrm{T} 11$ & $1.530 \mathrm{~d}$ & $2.669 \mathrm{~d}$ & $2.669 \mathrm{~d}$ & $1.192 \mathrm{~d}$ \\
Commercial fertilizer & $1.541 \mathrm{c}$ & $2.842 \mathrm{~b}$ & $2.842 \mathrm{~b}$ & $0.857 \mathrm{e}$ \\
control & $1.227 \mathrm{e}$ & $2.241 \mathrm{e}$ & $2.241 \mathrm{e}$ & $1.250 \mathrm{a}$ \\
\hline
\end{tabular}

A: absorbance

Compared to control, Trichoderma sp. isolates increased plant height by $24.4 \%$ (T4), $13.6 \%$ (T7) $10.8 \%$ (T11 and commercial preparation). These results are consistent with the studies of the researchers (Hoyos-Carvajal et al., 2009; Kaveh et al., 2011; Ousley et al., 1993). In plants inoculated with Trichoderma sp., the amount of root were increased (Ousley et al., 1993). Therefore plants receive more water and nutrients. In this study the applications with Trichoderma sp. were increased the root length of plant between 5.8 and 50.4\%. Datnofff and Pernezy (2001) explained that Trichoderma sp. increased the growth of tomato seedlings. In this study the the applications with Trichoderma sp. isolates were increased the root weight increased between 52 and 109\% (Table 1). The contents of photosynthetic pigment were increased in plants treated with Trichoderma sp. isolates (Table 2). The results are similar to those of the investigators (Ousley et al., 1993). 
Trichoderma isolates transformed minerals such as phosphorus, manganese, and copper iron into the soluble form (Altomare et al., 1999). Thus, roots can easily get the nutrients they need from the soil and the plant growth rate has increased (Küçük et al., 2008; Altomare et al., 1999). Yedidia et al. (2001) reported that T. harizanum applied cucumber; increased the $90 \%$ of phosphorus intake and 30\% increase in iron intake iron intake.

\section{Conclusion}

In this study, the effect of Trichoderma sp. isolates and commercially available Trichoderma harzianum on barley growth was evaluated. As a result; the establishment of the Trichoderma-plant interaction can support the biological control activities by revealing the defense mechanism of the host plant. Trichoderma sp. isolates may contribute to increasing plant growth by affecting the microbial population in the rhizosphere. In this study, it was determined that Trichoderma sp. isolates could be used in the growth of barley plants. The effects of the isolates tested on plant growth has been different. It was observed that the isolates had a positive effect on the plant growth characteristics of the barley plant. Trichoderma isolates have shown that they play a role as plant growth promoters. In future studies, it is necessary to determine the effects of Trichoderma sp. isolates on plant growth in stress conditions. Thus, the isolate or isolates of Trichoderma sp. that are effective can be an alternative to chemical fertilizers.

\section{REFERENCES}

[1] Akladious, S. A., Abbas, S. M. (2014): Application of Trichoderma harzianum T22 as a biofertilizer potential in maize growth. - Journal of Plant Nutrition 37: 30-49.

[2] Altomare, C., Norvell, W. A., Bjorkma, T. (1999): Solubilization of phosphate and micronutrients by the plant growth promoting and biocontrol fungus Trichoderma harzianum Rifai 1295-22. - Applied and Environmental Microbiology 65: 2926-2933.

[3] Bashan, Y. (1998): Inoculants of plant growth promoting bacteria for use in agriculture. Biotechnology Advances 16. 729-770.

[4] Bouyoucos, G. J. (1951): A recalibration of the hydrometer method for making mechanical analysis of soils. - Agronomy Journal 43: 435-438.

[5] Bremner, S. M. (1982): Total Nitrogen. - In: Page, A. L., Miller, R. H., Keeney, D. R. (eds.) Methods of Soil Analysis. Part 2. ASA-SSSA Madison, USA, pp. 595-624.

[6] Datnoff, L. E., Pernezny, K. L. (2001): Paenibacillus macerans and Trichoderma harzianum enhance transplant growth and suppress Fusarium crown and root rot in Florida tomato production. - 2001 Caribbean Division Meeting Abstracts, June 11-15, 2001, La Habana, Cuba. Publication No: P-2002-0025-Cra.

[7] de Santiago, A., Quintero, J. M., Aviles, M., Delgado, A. (2011): Effect of Trichoderma asperellum strain T34 on iron, copper, manganese and zinc uptake by wheat grown on a calcareous medium. - Plant and Soil 342: 97-104.

[8] Harman, G. E. (2006): Overview of mechanisms and uses of Trichoderma spp. Phytopathology 96: 190-194.

[9] Harman, G. E., Howell, C. R., Viterbo, A., Chet, I., Lorito, M. (2004): Trichoderma species-opportunistic, avirulent plant symbionts. - Nat. Rev. Microbiology 2: 43-56.

[10] Hermosa, R., Viterbo, A., Chet, I., Monte, E. (2012): Plant beneficial effects of Trichoderma and of its genes. - Microbiology 158: 17-25. 
[11] Hoyos-Carvajal, L., Orduz, S., Bissett, J. (2009): Growth stimulation in bean (Phaseolus vulgaris L.) by Trichoderma. - Biological Control 51: 409-416.

[12] Inbar, J., Abramsky, M., Cohen, D., Chet, I. (1994): Plant growth enhancement and disease control by Trichoderma harzianum in vegetable seedlings grown under commercial conditions. - European Journal of Plant Pathology 100: 337-346.

[13] Jalal, M. A. F., Love, S. K., Van der Helm, D. (1987): Siderophore mediated iron (III) uptake in Gliocladium virens (Trichoderma virens). 2. Role of ferric mono and dihydroxamates as iron transport agents. - Journal of Inorganic Biochemistry 29: 259267.

[14] Karakaya, A., Mert, Z., Oğuz, A. Ç., Çetin, L. (2016): Distribution of barley stripe disease in Central Anatolia, Turkey. - Selcuk Journal of Agriculture and Food Science 30: 59-61.

[15] Kaveh, H., Jartoodeh, S. V., Aruee, H., Mazhabi, M. (2011): Would Trichoderma affect seed germination and seedling quality of two muskmelon cultivars, Khatooni and Qasri and increase their transplanting success? - J. Biol. Environ. Sci. 5: 169-175.

[16] Kucharski, J., Ciecko, Z., Niewolak, T., Niklewska-Larska, T. (1996): Activity of microorganisms in soil of different agricultural usefullness complexes fertilized with mineral nitrogen. - Acta Acad. Agric. Technol. 62: 25-35.

[17] Küçük, Ç., Kıvanç, M., Kınacı, E., Kınacı, G. (2008): Determination of the growth and solubilization capabilities of Trichoderma harzianum T1. - Biologia, Bratislava 63(2): 162-170.

[18] Ousley, M. A., Lynch, J. M., Whipps, J. M. (1993): Effect of Trichoderma on plant growth: A balance between inhibition and growth promotion. - Microbiol. Ecology 26: 277-285.

[19] Raghothama, K. G. (1999): Phosphate acquisition. - Annual Review on Plant Physiology and Molecular Biology 50: 665-693.

[20] Rawat, L., Singh, Y., Shukla, N., Kumar, J. (2011): Alleviation of the adverse effects of salinity stress in wheat (Triticum aestivum L.) by seed biopriming with salinity tolerant isolates of Trichoderma harzianum. - Plant Soil 347: 387-400.

[21] Rennie, R., Heffer, P. (2003): Biology, innovation and the fertilizer industry is the change imperative? - The Fertilizer Industry Round Table, 27-29 October, pp.1-12.

[22] Sharma, A., Johri, B. N., Sharma, A., Glick, B. R. (2003): Plant growth promoting bacterium Pseudomonas sp. strains GRP3 influences iron acquisition in mung bean (Vigna radiata L. Wilzeck). - Soil Biology Biochemistry 35: 887-894.

[23] Shayakhmetov, L. F. (2001): Biological activity of metabolites from culture filtrate of Cochliobolus sativus and Fusarium oxysporum in connection with in vitro cellular selection of crop plants for resistance to phytopathogens. - Mycology and Phytopathology 35: 66-71.

[24] Shoresh, M., Harman, G. E., Mastouri, F. (2010): Induced systemic resistance and plant responses to fungal biocontrol agents. - Annu. Rev. Phytopathology 48: 21-43.

[25] Qi, W. Z., Zhao, L. (2012): Study of the siderophore producing Trichoderma asperellum Q1 on cucumber growth promotion under salt stress. - Journal of Basic Microbiology 53: 355-364.

[26] Vazquez, P., Holguin, G., Puente, M. E., Lopez-Cortez, A., Bashan, Y. (2000): Phosphate solubilizing microorganisms associated with the rhizosphere of mangroves in a semiarid coastal lagoon. - Biology Fertility Soils 30: 460-468.

[27] Vessey, J. K. (2003): Plant growth promoting rhizobacteria as biofertilizers. - Plant and Soil 255: 571-586.

[28] Viterbo, A., Landau, U., Kim, S. (2010): Characterization of ACC deaminase from the biocontrol and plant growth promoting agent Trichoderma asperellum T203. - FEMS Microbiology Letters 305: 42-48. 
[29] Walkey, A. (1964): A critical examination of a rapid method for determining organic carbon in soils effect of variations in digestion conditions and of inorganic soil constituents. - Soil Science 63: 251-263.

[30] Woo, S. L., scala, F., Ruocco, M., Lorito, M. (2006): The molecular biology of the interactions between Trichoderma spp., phytopathogenic fungi and plants. Phytopathology 96: 181-185.

[31] Yedidia, I., Srivastva, A. K., Kapulnik, Y., Chet, I. (2001): Effect of Trichoderma harzianum on microelement concentrations and increased growth of cucumber plants. Plant and Soil 235: 235-242.

[32] Zhang, F., Yuan, J., Yang, X., Cui, Y., Chen, L., Ran, W., Ran, W., Shen, Q. (2013): Putative Trichoderma harzianum mutant promotes cucumber growth by enhanced production of indole acetic acid and plant colonization. - Plant and Soil 368(1-2): 433444.

[33] Zhao, L., Zhang, Y. (2015): Effects of phosphate solubilization and phytohormone production of Trichoderma asperellum Q1 on promoting cucumber growth under salt stress. - Journal of Integrative Agriculture 14: 1588-1597. 